\title{
Zwinna transformacja w dużej skali
}

\author{
Dr hab. Paweł Wyrozębski, prof. SGH \\ Szkoła Główna Handlowa w Warszawie, Instytut Zarządzania \\ Katedra Zarządzania Projektami \\ Mgr Hubert Cichocki \\ Szkoła Główna Handlowa w Warszawie, Instytut Zarządzania \\ Katedra Zarządzania Projektami
}

\section{Wprowadzenie}

Zarządzanie projektami jest uznawane za jedną z najdynamiczniej rozwijających się dziedzin zarządzania. Wykorzystanie projektów jako narzędzia realizacji coraz większego zakresu celów przedsiębiorstw i organizacji nazwane zostało zjawiskiem projektyfikacji i badane jest od połowy lat dziewięćdziesiątych XX w przez licznych specjalistów z tej dziedziny ${ }^{1}$. Wraz z postępującą popularyzacją projektów i zarządzania projektami zaobserwować można jednocześnie wewnętrzne trendy i zróżnicowane kierunki zmian w ich ramach ${ }^{2}$. Zmiany te są odpowiedzią na nowe warunki i wyzwania, przed którymi stają współczesne przedsiębiorstwa i organizacje. W szczególności wyzwania te dotyczą tzw. Czwartej Rewolucji Przemysłowej oraz zmian niesionych przez cyfryzację społeczeństwa i gospodarki,

1 Ch. Midler, "Projectification” of the Firm: The Renault Case, „Scandinavian Journal of Management" 1995, vol. 11(4), s. 363-375; Y.-G. Schoper i wsp., Projectification in Western Economies: A Comparative Study of Germany, Norway and Iceland, ,International Journal of Project Management" 2017, http://dx.doi.org/10.1016/j.ijproman.2017.07.008; A. Nieto-Rodriguez, The Focused Organizations, Gower, London 2012; A. Wald i wsp., Towards a Measurement of "Projectification": A Study on the Share of Project-Work in the German Economy, [w:] A. Wald i wsp. (red.), Advanced Project Management: Flexibility and Innovative Capacity, „Neumarkt: GPM Deutsche Gesellschaft für Projektmanagement”, vol. 4, GPM, Nürnberg 2015, s. 18-36; M. Trocki, Projekty w organizacji - problem i wyzwania strategiczne, [w:] Z. Dworzecki, G. Leśniak-Łebkowska (red.), Księga jubileuszowa dla Profesor Marii Romanowskiej, Oficyna Wydawnicza SGH - Szkoła Główna Handlowa w Warszawie, Warszawa 2017, s. 195-213.

2 R. Thomsett, Radical Project Management, Prentice Hall, Upper Saddle River 2002. 
czyli tzw. Gospodarkę/Przemysł $4.0^{3}$ oraz tzw. wywrotowe technologie (disruptive technologies) ${ }^{4}$.

W ostatnich latach popularność zyskała koncepcja oddająca obserwowany wzrost dynamiki otoczenia - tzw. model VUCA. Został on opracowany jeszcze $\mathrm{w}$ końcu lat osiemdziesiątych XX wieku i był z powodzeniem stosowany w kolejnych dekadach na potrzeby Armii Stanów Zjednoczonych w celu szkolenia oficerów, którzy mieli być w lepszym stopniu przygotowani na dynamikę i wyzwania postzimnowojennego pola walki ${ }^{5}$. Według W.E. Whitemana, który przytacza z kolei tezy O.G. Minka: „W sytuacjach, które charakteryzują warunki, takie jak zmienność (ang. volatility), niepewność (ang. uncertainty), złożoność (ang. complexity) oraz niejednoznaczność (ang. ambiguity), koniecznym jest budowanie struktur organizacyjnych w sposób odpowiadający wyzwaniom stawianym przez takie środowisko" 6 . Problemy te dostrzegane są w perspektywie wszystkich obszarów zarządzania współczesnymi organizacjami, w tym także przez praktyków i badaczy z dziedziny zarządzania projektami. W kolejnych raportach Project Management Institute, największego globalnego stowarzyszenia profesjonalistów zarządzania projektami, jednoznacznie wskazuje się na konieczność wdrażania zmian w strukturach organizacyjnych, zgodnych z duchem Whitemana, tj. wspierających kulturę przywództwa nastawionego na współpracę, nakierowanych na ciągłe uczenie się, pełne zaangażowanie pracowników,

3 M. Hermann, T. Pentek, B. Otto, Design Principles for Industrie 4.0 Scenarios: A Literature Review, Technische Universität Dortmund, Fakultät Maschinenbau, Dortmund 2015; BCG, Industry 4.0: The Future of Productivity and Growth in Manufacturing Industries, 2015, https://www .bcg.com (dostęp: 20.01.2020); J. Pieriegud, Cyfryzacja gospodarki i spoteczeństwa- wymiar globalny, europejski i krajowy, [w:] J. Gajewski, W. Paprocki, J. Pieriegud (red.), Cyfryzacja gospodarki i spoteczeństwa - szanse i wyzwania dla sektorów infrastrukturalnych, Instytut Badań nad Gospodarką Rynkową - Gdańska Akademia Bankowa, Gdańsk 2016; R. Berger, The digital transformation of industry, Federation of German Industries (BDI) \& Roland Berger Strategy Consultants, Berlin 2015, www.rolandberger.com (dostęp: 20.01.2020); PWC, Industry 4.0: Building the digital enterprise, 2016 Global Industry 4.0 Survey, www.pwc.com (dostęp: 20.01.2020).

4 T. Zaręba, Self aware networks - cechy techniczne i implikacje technologiczne, [w:] J. Gajewski, W. Paprocki, J. Pieriegud (red.), Cyfryzacja gospodarki i społeczeństwa-szanse i wyzwania dla sektorów infrastrukturalnych, Instytut Badań nad Gospodarką Rynkową - Gdańska Akademia Bankowa, Gdańsk 2016; C.M. Christensen, Przełomowe innowacje, Wydawnictwa Profesjonalne PWN, Warszawa 2010.

5 US. Army Heritage \& Education Center, http://usawc.libanswers.com/faq/84869 (dostęp: 31.01.2020).

$6 \quad$ O.G. Mink i wsp., Change at Work: A Comprehensive Management Process for Transforming Organizations, Jossey-Bass Publishers, San Francisco 1993, s. 54-55, za: W.E. Whiteman, Training and educating army officers for the $21^{\text {st }}$ century: Implications for the United States Military Academy, Defense Technical Information Center, Fort Belvoir 1998, s. 15. 
dostarczanie wartości, wsparcia zwinności organizacyjnej czy stworzenia warunków do odważniejszego eksperymentowania $\mathrm{z}$ innowacjami ${ }^{7}$. W zarysowane powyżej problemy zarządzania organizacjami w doskonały sposób wpisuje się rozwiązanie znane w zarządzaniu projektami od początku lat dziewięćdziesiątych XX wieku, tj. tzw. podejście zwinne (agile project management). Początkowo podejście to wyrażało sprzeciw programistów wobec założeń tzw. tradycyjnego zarządzania projektami, traktowanych jako sztywne i oparte na mikrozarządzaniu zespołem, z czasem docenione zostało jako praktyczny zbiór metod i praktyk zarządzania, realizujących założenia uelastycznienia organizacji, budowania zdolności do zmian, adaptacyjności do niestabilnych warunków otoczenia oraz wzmocnienia pozycji silnie zintegrowanych, zorientowanych na rezultaty, płaskich, samoorganizujących się zespołów zadaniowych. Wśród zasad realizowanych w praktyce przez metodyki zwinne wskazać można te wprost korespondujące $z$ założeniami przedsiębiorstwa w świecie VUCA. Zwinne metodyki zarządzania projektami są źródłem praktycznych zaleceń odnoszących się do sposobu działania zespołów zadaniowych. Ich poznanie i wdrożenie jako modelu realizacji projektów buduje szereg kompetencji organizacji. Według Command and Control Research Program Departamentu Obrony USA są to takie zdolności jak: zdolność reakcji (responsiviness) - reagowania na czas na zmiany otoczenia, wszechstronność (versatility) - zdolność do efektywnej realizacji zadań w różnych sytuacjach i warunkach, elastyczność (flexibility) - możliwość korzystania z wielu rozwiązań i płynnego przejścia od jednego do drugiego, prężność (resilience) - zdolność radzenia sobie z nieszczęśliwymi wypadkami, szkodami lub destabilizującymi zakłóceniami otoczenia lub dostosowanie się do nich, zdolność innowacyjna (innovativeness) - zdolność do robienia nowych rzeczy i zdolność do robienia starych rzeczy w nowy sposób, zdolność adaptacji (adaptability) - możliwość zmiany procesów pracy i zdolność do zmiany organizacji ${ }^{8}$.

7 PMI, Accenture, Forging the Future: Evolving with Disruptive Technologies, Project Management Institute, Thought Leadership Series 2018, https://www.pmi.org/learning/thought -leadership/series (dostęp: 20.01.2020); PMI, KPMG, Achieving Greater Agility. The Vital Role of Culture and Commitment, Project Management Institute, Thought Leadership Series 2017, https://www.pmi.org/learning/thought-leadership/series (dostęp: 20.01.2020); PMI, PMI's Pulse of the Profession $11^{\text {th }}$ Global Project Management Survey: The future of Work. Leading the Way with PMTQ, Project Management Institute 2019, https://www.pmi.org/learning/th ought-leadership/pulse (dostęp: 20.01.2020).

8 D.S. Alberts, R.E. Hayes, Power to the Edge, DoD Command and Control Research Program 2009, www.dodccrp.org (dostęp: 20.01.2020); D.S. Alberts, The Agility Advantage, DoD Command and Control Research Program 2011, www.dodccrp.org (dostęp: 20.01.2020). 
Atrakcyjność podejścia zwinnego w zarządzaniu projektami oraz liczne, opisane w literaturze korzyści dla organizacji, wynikające z zastosowania go w realizacji projektów i tworzeniu nowych rozwiązań ${ }^{9}$, stały się przyczyną coraz szerszej adaptacji i skalowania metodyk zwinnych z poziomu pojedynczych, małych zespołów do poziomu całej zwinnie zarządzanej organizacji ${ }^{10}$. Proces wdrożenia i przebudowy istniejących rozwiązań organizacyjnych w kierunku „uzwinnienia” organizacji nazywany jest w literaturze i praktyce „transformacją agile” lub „transformacją agilową"11. Wychodząc z powyższych założeń, celem niniejszego artykułu jest prezentacja problemów, na które napotykają współczesne organizacje w procesie opisanych zmian - omówienie zagadnień związanych ze zwinną transformacją w dużej organizacji, w szczególności barier we wdrożeniu zmian.

\section{Istota zwinności w dużej skali (large-scale agile)}

W pierwszej kolejności należałoby rozważyć to, czym jest zwinne zarządzanie w dużej organizacji czy dużej skali. Uczestnicy konferencji XP2014, w celu ustalenia spójnej definicji, dokonali wspólnej konceptualizacji tego pojęcia. Wśród propozycji pojawiały się następujące definicje ${ }^{12}$ :

- więcej niż pięćdziesięciu deweloperów lub więcej niż pół miliona linii kodu, lub więcej niż trzy strefy czasowe;

- więcej niż pięćdziesięciu uczestników, więcej niż pięć zespołów, które jednocześnie rozwijają ten sam produkt lub projekt;

- zwinność aplikowana do więcej niż jednego zespołu, projektu lub produktu;

- aplikacja zwinności na poziomie organizacji jako całości;

9 G. Benefield, Rolling out Agile at large Enterprise, [w:] J. Sutherland, K. Schwaber, The Scrum Papers: Nuts, Bolts, and Origins of an Agile Process, www.scrumtraininginstitute .com (dostęp: 20.01.2020); J. Sutherland, C. Jacobson, K. Johnson, Scrum and CMMI Level 5: A Magic Potion for Code Warriors!, Agile Conference, Washington 2007; CHAOS Manifesto 2013, Think Big, Act Small, The Standish Group International, Incorporated 2013, www.stan dishgroup.com (dostęp: 20.01.2020); VersionOne, The 10 th Annual State of Agile Report 2015, www.versionone.com (dostęp: 10.04.2017).

10 P. Wyrozębski, Zwinne koncepcje i modele planowania przebiegu projektów, [w:] M. Trocki, P. Wyrozębski (red.), Planowanie przebiegu projektu, Oficyna Wydawnicza SGH - Szkoła Główna Handlowa w Warszawie, Warszawa 2015; H. Portman, Will the PMO disappear in the scaling agile world?, Konferencja Portfolio Experience, Warszawa 2017.

11 L. Barroca, T. Dingsøyr, M. Mikalsen, Agile Transformation: A Summary and Research Agenda from the First International Workshop, http://dx.doi.org/10.1007/978-3-030-30126-2_1.

12 T. Dingsøyr, N.B. Moe, Towards Principles of Large-Scale Agile Development: A Summary of the workshop at XP2014 and a revised research agenda, International Conference on Agile Software Development, Springer, Cham 2014. 
- zarządzanie zwinne w kontekście zadania, gdzie zaangażowanych jest więcej zespołów, niż jedna osoba jest w stanie zarządzać, oraz produkt jest na tyle skomplikowany, że kilka zespołów projektowych nie jest w stanie mu podołać;

- wiele zespołów pracujących razem w celu dostarczenia produktów software.

W literaturze przedmiotu można wyróżnić cztery kategorie interpretacyjne dotyczące aplikacji metodyk zwinnych w dużej skali13:

- wykorzystanie metodyk zwinnych w dużych firmach,

- aplikacja metodyk zwinnych w dużych projektach lub dużych zespołach projektowych,

- stosowanie metodyk zwinnych w środowisku wielozespołowym,

- wykorzystanie pryncypiów oraz praktyk metodyk zwinnych w firmie jako całości.

\section{Pryncypia transformacji agile w dużej skali}

Podsumowania wyzwań w kluczowych obszarach transformacji agile w dużych organizacjach dokonali T. Dingsøyr i N.B. Moe. W pierwszej kolejności zwrócili oni uwagę na rolę architektury, która - ich zdaniem - ma kluczowe znaczenie w koordynowaniu wkładów deweloperskich, oraz na fakt, że poziom niepewności i zakres zmian będą kluczowymi determinantami wpływu na sposób projektowania architektury w organizacji zwinnej. Kolejnym zagadnieniem jest koordynacja zespołów w organizacji. Zwracając uwagę na to, że zwinność w dużej skali wymaga koordynacji zespołów na dwóch poziomach, tj. w ramach zespołu oraz między różnymi zespołami, zaproponowali narzędzia koordynacji, tj. ustanowienie wspólnych norm i wartości w celu lepszego porozumienia między zespołami oraz efektywnych narzędzi dzielenia się wiedzą między zespołami. Trzecim zagadnieniem poruszanym przez tych autorów jest zarządzanie portfolio. Podkreślili oni, że kluczowym zagadnieniem w tym obszarze jest kontrola nad działaniami i decyzjami członków zespołu, tak aby realizowali działania zgodne z celami organizacji. Jako pryncypia zarządzania portfolio wymienili ciągłe przekazywanie informacji zwrotnych z poziomu zarządzania portfolio na poziom zespołów, aby zachować spójność między działaniami członków zespołów a celami portfolio oraz ciągłe przekazywanie informacji z poziomu zespołów na poziom zarządzania portfolio w celu optymalizacji wartości całego portfolio. Czwarty obszar wyzwań to skalowanie zwinności w organizacji. Autorzy zaproponowali dwa pryncypia skalowania, tj. konieczność właściwego opisu kontekstu i środowiska, co jest kluczowe dla wdrażania skalowania zwinności z sukcesem, oraz fakt, że powinno się

13 Ch. Fuchs, T. Hess, Becoming agile in the digital transformation: the process of a large-scale agile transformation, Proceedings of the $39^{\text {th }}$ International Conference on Information Systems (ICIS 2018), San Francisco 2018. 
skalować, biorąc pod uwagę zarówno liczbę zaangażowanych zespołów, jak i aktywność związaną z inżynierią oprogramowania, ponieważ są one współzależne ${ }^{14}$.

W literaturze istotne miejsce zajmują prace dotyczące rozwoju teorii aspektów ludzkich w transformacji agile. Jako kluczowe elementy tej teorii badacze proponują następujące obszary ${ }^{15}$ :

- czynnik ludzki jako przeszkoda w transformacji - tj. takie elementy jak kwestie kulturowe, brak wiedzy, odporność na zmiany, niekorzystne nastawienie, brak współpracy;

- czynnik ludzki jako wzmacniacz transformacji - wśród czynników wzmacniających można wymienić zaangażowanie pracowników, zaangażowanie kierowników i kierownictwa, pozytywną rolę przywództwa oraz liderów zmiany, a także rolę osób wspierających transformację;

- percepcja transformacji - tj. kwestie związane z poziomem entuzjazmu dla wprowadzania zmian, strachu przed zmianą, obojętnością w stosunku do zmiany, realnymi potrzebami zmian oraz nierealistycznymi oczekiwaniami w stosunku do efektów wdrożenia transformacji zwinnej

- czynniki motywujące do wprowadzania zmian.

\section{Bariery transformacji agile w dużej skali}

Transformację agile $\mathrm{w}$ dużej organizacji należy rozumieć jako przejście z niezwinnego podejścia do rozwoju oprogramowania lub innej koncepcji organizacji pracy do metod zwinnych. Istnieją dwie ścieżki takiej transformacji, tj. jeden transfer do metod zwinnych, rozumiany jako przejście do metod zwinnych całej organizacji lub całej jednostki organizacyjnej, lub wdrożenie etapami, gdzie krok po kroku wprowadzane są rozwiązania zwinne. W praktyce wdrożenie może przyjąć formęl6:

- zatrudnienia pracowników, którzy wspierają proces wdrażania zwinności,

- przekształcania kolejnych jednostek biznesowych,

- poszerzenia zwinności, tj. integracji wcześniejszych praktyk zwinnych z nowymi metodami zwinnymi.

Wobec faktu, że agile jest sposobem myślenia, a nie zestawem narzędzi czy praktyk, transformacja agile często wymaga wdrożenia zmiany w kulturze

14 T. Dingsøyr, N.B. Moe, Towards Principles...

15 T.J. Gandomani i wsp., How Human Aspects Impress Agile Software Development Transition and Adoption, „International Journal of Software Engineering and Its Applications” 2014, vol. 8, no. 1, s. $129-148$.

16 T. Dingsøyr, N.B. Moe, Towards Principles... 
organizacyjnej17. Należy także pamiętać, że duże organizacje cechują się zwykle wyższym poziomem inercji organizacyjnej oraz dodatkowymi barierami dla wpro-

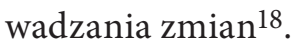

Uwagę na bariery we wdrażaniu zmian w organizacji zwracają S. Rosenberg i J. Mosca. Wymieniają wśród nich między innymi dysfunkcjonalną kulturę organizacyjną, wielkość organizacji i jej „sztywność”, politykę organizacyjną czy wewnątrzorganizacyjny konflikt o zasoby ${ }^{19}$. W literaturze podkreśla się także rolę interesariuszy $\mathrm{w}$ transformacji agile ${ }^{20}$, która prawdopodobnie jest tym bardziej istotna, im większa jest organizacja. Jest to trywialna obserwacja, jednak im większa jest dana organizacja, tym większa liczba interesariuszy jest zaangażowana w jej działalność. Są to nie tylko organy wewnętrzne spółki i pracownicy, ale często także przedstawiciele rządu, regulatorzy, stowarzyszenia biznesowe czy instytucje typu watchdog.

Inni autorzy wyróżniają cztery grupy barier związanych z transformacją agile ${ }^{21}$ :

- bariery związane z organizacją, takie jak kultura, komunikacja, obowiązki dokumentacyjne i raportowe, a także balans władztwa między kierownikami a pracownikami;

- bariery związane zzasobami ludzkimi, tj. w relacji do pracowników i użytkowników;

- bariery procesowe, wśród których wyróżnia się praktyki pomiaru sprawności wykonywania zadań, sposoby przejścia z tradycyjnego modelu cyklu życia do metodyk zwinnych, a także wybór właściwej metodyki zwinnej;

- bariery związane z technologią i narzędziami transformacji, takie jak oprogramowanie oraz sprzęt niekorespondujący z potrzebami wynikającymi ze wdrożenia metody zwinnych.

Na problemy związane z rozbudowanymi obowiązkami dokumentacyjnymi, zwiększeniem wyzwań wynikających z koordynacji między wieloma zespołami pracowniczymi w przypadku skalowania zwinności, konieczność koordynacji prac z biznesowymi jednostkami wsparcia, które nie funkcjonują w ramach kultury

17 S. C. Misra, V. Kumar, U. Kumar, Identifying some critical changes required in adopting agile practices in traditional software development projects, „International Journal of Quality \& Reliability Management" 2010, vol. 27(4).

18 J.A. Livermore, Factors that Significantly Impact the Implementation of an Agile Software Development Methodology, „Journal of Software” 2008, vol. 3(4), s. 31-36.

19 S. Rosenberg, J. Mosca, Breaking Down The Barriers To Organizational Change, „International Journal of Management \& Information Systems" 2011, vol. 15, no. 3.

20 T.J. Gandomani i wsp., Towards Comprehensive and Disciplined Change Management Strategy in Agile Transformation Process, „Research Journal of Applied Sciences, Engineering and Technology" 2013, vol. 6(13), s. 2345-2351.

21 T.J. Gandomani i wsp., Obstacles in Moving to Agile Software Development Methods; At a Glance, „Journal of Computer Science” 2013, vol. 9(5), s. 620-625. 
agile, a także zbyt rozległy proces planistyczny oraz rolę związanej z nim kultury, zwracają uwagę również inni autorzy ${ }^{22}$.

\section{Zakończenie}

Zwinność w zarządzaniu projektami i innowacjami produktowymi stanowiła czynnik rewolucjonizujący współczesne przedsiębiorstwa. Popularyzacja nowego podejścia umożliwiła przyspieszenie tempa opracowywania nowych rozwiązań, podniosła ich jakość i innowacyjność, a przede wszystkim skróciła czas ich wdrożenia na rynek ${ }^{23}$. Siłą zwinnego zarządzania organizacją zdaje się jednak bardziej być nowa, otwarta kultura organizacyjna niż same narzędzia i techniki zwinnego zarządzania. Według ekspertów Project Management Institute - dr R. McGrath oraz T. Scotta - kluczowymi aspektami zwinności pozostają wzajemne zaufanie i kwestia przywództwa oraz wyższej tolerancji ryzyka ${ }^{24}$. O ile zatem relatywnie łatwiej zmieniać środowisko i kulturę w pierwotnie adresowanych przez agile małych, silnie zintegrowanych zespołach, o tyle jednak przeniesienie tych zasad na całe organizacje staje się dużym wyzwaniem, na którego drodze staje wiele opisanych w artykule barier. Według autorów niniejszego artykułu jest to niezwykle interesujący i przyszłościowy obszar badawczy, wart kolejnych studiów. Jego całościowe rozpoznanie i opisanie mogłoby umożliwić w przyszłości sformułowanie kompleksowych zaleceń dotyczących doskonalenia organizacji zgodnie z duchem zwinności.

\section{Bibliografia}

Alberts D.S., The Agility Advantage, DoD Command and Control Research Program 2011, http://www.dodccrp.org/files/agility_advantage/Agility_Advantage_Book.pdf (dostęp: 20.01.2020).

Alberts D.S., Hayes R.E., Power to the Edge, DoD Command and Control Research Program 2009, http://www.dodccrp.org/files/Alberts_Power.pdf (dostęp: 20.01.2020).

Barroca L., Dingsøyr T., Mikalsen M., Agile Transformation: A Summary and Research Agenda from the First International Workshop, http://dx.doi.org/10.1007/978-3-030-30126-2_1

22 K. Dikert, M. Paasivaara, C. Lassenius, Challenges and success factors for large-scale agile transformations: A systematic literature review, „Journal of Systems and Software”, September 2016, vol. 119, s. 87-108.

23 D.K. Rigby, J. Sutherland, H. Takeuchi, Embracing Agile, „Harvard Business Review”, May 2016.

24 PMI, KPMG, Achieving Greater Agility... 
BCG, Industry 4.0: The Future of Productivity and Growth in Manufacturing Industries, 2015, https:// www.bcg.com/pl-pl/publications/2015/engineered_products_project_business_indust ry_4_future_productivity_growth_manufacturing_industries.aspx (dostęp: 20.01.2020).

Benefield G., Rolling out Agile at large Enterprise, [w:] J. Sutherland, K. Schwaber, The Scrum Papers: Nuts, Bolts, and Origins of an Agile Process, http://www.scruminc.com/scrumpapers .pdf (dostęp: 20.01.2020).

Berger R., The digital transformation of industry, Federation of German Industries (BDI) \& Roland Berger Strategy Consultants, Berlin 2015, https://bdi.eu/media/user_upload/Digital_Trans formation.pdf (dostęp: 20.01.2020).

CHAOS Manifesto 2013, Think Big, Act Small, The Standish Group International, Incorporated, 2013, http://athena.ecs.csus.edu/ buckley/CSc231_files/Standish_2013_Report.pdf (dostęp: 20.01.2020).

Christensen C.M., Przełomowe innowacje, Wydawnictwa Profesjonalne PWN, Warszawa 2010.

Dikert K., Paasivaara M., Lassenius C., Challenges and success factors for large-scale agile transformations: A systematic literature review, „Journal of Systems and Software”, September 2016, vol. 119, s. 87-108.

Dingsøyr T., Moe N.B., Towards Principles of Large-Scale Agile Development: A Summary of the workshop at XP2014 and a revised research agenda, International Conference on Agile Software Development, Springer, Cham 2014.

Fuchs Ch., Hess T., Becoming agile in the digital transformation: the process of a large-scale agile transformation, Proceedings of the 39th International Conference on Information Systems (ICIS 2018), San Francisco 2018.

Gandomani T.J., Zulzalil H., Ghani A.A.A., Sultan A.B. Md., Towards Comprehensive and Disciplined Change Management Strategy in Agile Transformation Process, „Research Journal of Applied Sciences, Engineering and Technology" 2013, vol. 6(13), s. 2345-2351.

Gandomani T.J., Zulzalil H., Ghani A.A.A., Sultan A.B. Md., Nafchi M.Z., Obstacles in Moving to Agile Software Development Methods; At a Glance, „Journal of Computer Science” 2013, vol. 9(5), s. 620-625.

Gandomani T.J., Zulzalil H., Ghani A.A.A., Sultan A.B. Md., Yatim K., How Human Aspects Impress Agile Software Development Transition and Adoption, „International Journal of Software Engineering and Its Applications" 2014, vol. 8, no. 1, s. 129-148.

Hermann M., Pentek T., Otto B., Design Principles for Industrie 4.0 Scenarios: A Literature Review, Technische Universität Dortmund, Fakultät Maschinenbau, Dortmund 2015.

Livermore J.A., Factors that Significantly Impact the Implementation of an Agile Software Development Methodology, „Journal of Software” 2008, vol. 3(4), s. 31-36.

Midler Ch., "Projectification” of the Firm: The Renault Case, „Scandinavian Journal of Management 1995, vol. 11(4), s. 363-375.

Mink O.G., Esterhuysen P.W., Mink B.P., Owen K.Q., Change at Work: A Comprehensive Management Process for Transforming Organizations, Jossey-Bass Publishers, San Francisco 1993.

Misra S. C., Kumar V., Kumar U., Identifying some critical changes required in adopting agile practices in traditional software development projects, „International Journal of Quality \& Reliability Management" 2010, vol. 27(4), s. 451-474.

Nieto-Rodriguez A., The Focused Organizations, Gower, London 2012.

Pieriegud J., Cyfryzacja gospodarki i społeczeństwa - wymiar globalny, europejski i krajowy, [w:] J. Gajewski, W. Paprocki, J. Pieriegud (red.), Cyfryzacja gospodarki i społeczeństwa - szanse i wyzwania dla sektorów infrastrukturalnych, Instytut Badań nad Gospodarką Rynkową - Gdańska Akademia Bankowa, Gdańsk 2016, s. 11-37. 
PMI, Accenture, Forging the Future: Evolving with Disruptive Technologies, Project Management Institute, Thought Leadership Series 2018, https://www.pmi.org/learning/thought-leader ship/series (dostęp: 20.01.2020).

PMI, KPMG, Achieving Greater Agility. The Vital Role of Culture and Commitment, Project Management Institute, Thought Leadership Series 2017, https://www.pmi.org/learning/thought-le adership/series (dostęp: 20.01.2020).

PMI, PMI's Pulse of the Profession $11^{\text {th }}$ Global Project Management Survey: The future of Work. Leading the Way with PMTQ, Project Management Institute 2019, https://www.pmi.org/learning /thought-leadership/pulse (dostęp: 20.01.2020).

Portman H., Will the PMO disappear in the scaling agile world?, Konferencja Portfolio Experience, Warszawa 2017.

PWC, Industry 4.0: Building the digital enterprise, 2016 Global Industry 4.0 Survey, https://www .pwc.com/gx/en/industries/industries-4.0/landing-page/industry-4.0-building-your-digit al-enterprise-april-2016.pdf (dostęp: 20.01.2020).

Rigby D.K., Sutherland J., Takeuchi H., Embracing Agile, „Harvard Business Review”, May 2016, https://hbr.org/2016/05/embracing-agile (dostęp: 20.01.2020).

Rosenberg S., Mosca J., Breaking Down The Barriers To Organizational Change, „International Journal of Management \& Information Systems" 2011, vol. 15, no. 3. s. 139-146.

Schoper Y.-G., Wald A., Ingason H.T., Fridgeirsson T.V., Projectification in Western Economies: A Comparative Study of Germany, Norway and Iceland, „International Journal of Project Management" 2017, http://dx.doi.org/10.1016/j.ijproman.2017.07.008.

Sutherland J., Jacobson C., Johnson K., Scrum and CMMI Level 5: A Magic Potion for Code Warriors!, Agile Conference, Washington 2007.

Thomsett R., Radical Project Management, Prentice Hall, Upper Saddle River 2002.

Trocki M., Projekty w organizacji - problem i wyzwania strategiczne, [w:] Z. Dworzecki, G. Leśniak-Łebkowska (red.), Księga jubileuszowa dla Profesor Marii Romanowskiej, Oficyna Wydawnicza SGH - Szkoła Główna Handlowa w Warszawie, Warszawa 2017, s. 195-213.

US. Army Heritage \& Education Center, http://usawc.libanswers.com/faq/84869 (dostęp: 31.01.2020).

VersionOne, The 10 ${ }^{\text {th }}$ Annual State of Agile Report 2015, http://www.agile247.pl/wp-content/up loads/2016/04/VersionOne-10th-Annual-State-of-Agile-Report.pdf (dostęp: 10.04.2017).

Wald A., Schneider C., Spanuth T., Schoper Y., Towards a Measurement of "Projectification": A Study on the Share of Project-Work in the German Economy, [w:] A. Wald, R. Wagner, C. Schneider, M. Gschwendtner (red.), Advanced Project Management: Flexibility and Innovative Capacity, „Neumarkt: GPM Deutsche Gesellschaft für Projektmanagement”, vol. 4, GPM, Nürnberg 2015, s. 18-36.

Whiteman W.E., Training and educating army officers for the $21^{\text {st }}$ century: Implications for the United States Military Academy, Defense Technical Information Center, Fort Belvoir 1998.

Wyrozębski P., Zwinne koncepcje i modele planowania przebiegu projektów, [w:] M. Trocki, P. Wyrozębski (red.), Planowanie przebiegu projektu, Oficyna Wydawnicza SGH - Szkoła Gtówna Handlowa w Warszawie, Warszawa 2015, s. 209-228.

Zaręba T., Self aware networks - cechy techniczne i implikacje technologiczne, [w:] J. Gajewski, W. Paprocki, J. Pieriegud (red.), Cyfryzacja gospodarki i społeczeństwa - szanse i wyzwania dla sektorów infrastrukturalnych, Instytut Badań nad Gospodarką Rynkową - Gdańska Akademia Bankowa, Gdańsk 2016, s. 75-90. 


\section{Streszczenie}

Bariery transformacji agile wzrastają wraz z wielkością organizacji, pojawiają się także nowe - charakterystyczne dla dużych organizacji. Celem niniejszego artykułu jest omówienie zagadnień związanych ze zwinną transformacją w dużej organizacji, w szczególności barier we wdrażaniu zmian. Realizacji tego celu służy badanie literaturowe. Wśród obszarów kluczowych dla skutecznej transformacji agile wymienia się architekturę, koordynację między zespołami, proces skalowania oraz zarządzanie portfolio.

Słowa kluczowe: zarządzanie projektami, zwinność, agile, transformacja agile, skalowanie agile, agile w dużej skali

\section{Large scale agile transformation}

\section{Abstract}

Agile transformation barriers increase with the size of the organization, as well as new, specific for large organizations ones are emerging. The purpose of this article is to discuss issues related to agile transformation in a large organizations, in particular barriers to implementing change. Literature research serves this purpose. Key areas for successful agile transformation include architecture, coordination between teams, scaling process and portfolio management.

Keywords: project management, agile, agile transformation, agile scaling, large scale agile 